\title{
Durability of fiber-post and resin core build-up systems
}

\author{
Masayuki HATTORI, Shinji TAKEMOTO, Masao YOSHINARI, Eiji KAWADA and Yutaka ODA
}

Department of Dental Materials Science, Tokyo Dental College, 1-2-2 Masago, Mihama-ku, Chiba 261-8502, Japan

Corresponding author, Masayuki HATTORI; E-mail: hattori@tdc.ac.jp

\begin{abstract}
The aim of this study was to evaluate the durability of unidirectional and bidirectional fiber-reinforced post systems under static and cyclic loading. Three prefabricated fiber posts with one of two core composite resins each or a post resin were used. Each specimen was subjected to a three-point bending test after cyclic loading (1000 times) by $0.1,0.2$ or $0.3 \mathrm{~mm}$ deflection. Under cyclic loading, flexure strength and elastic modulus tended to show a decrease with increase in deflection in the unidirectional fiber post specimens. No such tendency, however, was observed in the bidirectional fiber post specimen. In conclusion, use of a prefabricated fiber post in a post-and-core complex improved the flexural properties of the core composite resin, regardless of fiber direction. Although deterioration in flexural properties was observed with cyclic loading in the unidirectional fiber post specimens, no significant difference was observed in the bidirectional fiber post specimen.
\end{abstract}

Keywords: Durability, Fiber post, Resin core

Received Nov 9, 2009: Accepted Dec 24, 2009

\section{INTRODUCTION}

Recently, fiber-reinforced composite (FRC) post-andcore systems have come to be widely used in the restoration of endodontically treated teeth ${ }^{1}$. FRC posts offer a number of advantages over metal posts due to their modulus of elasticity being closer to that of dentin and superior esthetic quality. Teeth restored with FRC posts show better resistance to fracture propagation than teeth restored with prefabricated or cast metal posts ${ }^{2}$. Endodontically treated teeth reinforced with a prefabricated fiber post have shown lower incidences of root fracture ${ }^{3,4)}$.

FRC posts contain a high volume percentage of continuous reinforcing glass fibers embedded in a polymer matrix, which holds the fibers together. The matrix commonly comprises epoxy or acrylic polymers with or without filler materials. The fibers used in FRC posts may be classified according to fiber directionunidirectional or bi-directional-or whether they are pre-impregnated with unfilled resin or filled resin. The stability of the fiber/polymer matrix and fiber post/core resin interface must be taken into consideration in evaluating the clinical longevity of FRC posts.

Several studies have investigated the influence of the mechanical properties of post-and-core components on the flexural strength of a prefabricated fiber post ${ }^{5-8}$. One study investigated adhesion between core composite resin and prefabricated fiber post ${ }^{9}$. To our knowledge, however, few studies have investigated the effect of cyclic loading on durability in FRC posts. The aim of this study was to evaluate the durability of unidirectional and bidirectional fiber-reinforced post systems under static and cyclic loading.

\section{MATERIALS AND METHODS}

Commercially available posts and core systems were chosen for this study. Three prefabricated fiber posts
(Table 1, Figs. 1-2) —and three core composite resins were used (Table 2). Each core composite resin or post resin with prefabricated fiber post $(2.0 \mathrm{~mm}$ in diameter and $20.0 \mathrm{~mm}$ in length) was subjected to a three-point bending test after cyclic loading by $0.1,0.2$ and $0.3 \mathrm{~mm}$ deflection.

Sample preparation for composite resin with prefabricated fiber post

The preparation procedure for the composite resin with prefabricated fiber post specimens is shown in Fig. 3. An acrylic pipe $(2.0 \mathrm{~mm}$ in diameter and $20.0 \mathrm{~mm}$ in length) which was coated by mold releasing agent (DAIFREE, Daikin Industries, Ltd. Osaka, Japan) was filled with composite resin to form a core. Two brass lids with holes in $(1.5 \mathrm{~mm}$ in diameter) were then pressed onto either end of the pipe to squeeze out any excess resin. The prefabricated fiber posts were used as received length, however in case of i-TFC, the fiber post was cut in length of $24 \mathrm{~mm}$ using diamond disk because the product was $45 \mathrm{~mm}$. After treating the prefabricated fiber post surface according to the manufacturer's instructions, the prefabricated fiber post was carefully inserted into the pipe through the center holes in the lids. Light-exposure was performed for $60 \mathrm{sec}$ by placing the tip of a light source (Grip light, Shofu, Kyoto, Japan) along the long axis of the pipe at $6-\mathrm{mm}$ intervals. A total of 6 times and $360 \mathrm{sec}$ was performed for light curing of one composite resin with prefabricated fiber post specimen. Specimens without an FRC post were also prepared to evaluate the composite resins alone. All specimens were stored in water for $24 \mathrm{hr}$ at $37^{\circ} \mathrm{C}$.

Three-point bending test and cyclic loading test

A three-point bending test was performed according to the ISO10477 standard (span, $15.0 \mathrm{~mm}$; crosshead speed, $1.0 \mathrm{~mm} / \mathrm{min}$; cross-sectional diameter of loading tip, $5 \mathrm{~mm}$ ) to measure the fracture strength of the 
Table 1 Prefabricated fiber posts used in this study

\begin{tabular}{|c|c|c|c|c|c|}
\hline Brand name & Manufacturer & Composition & Dia.(mm) & Type & Code \\
\hline GC Fiber Post & GC Corp. & $\begin{array}{l}\text { Glass fibers } \\
\text { Methacrylate ester and/or Bis-GMA } \\
\text { copolymer }\end{array}$ & 1.20 & unidirectional & GCF \\
\hline FibreKor Post & Pentron Corp. & $\begin{array}{l}\text { Glass fibers } \\
\text { Bis-GMA } \\
\text { Filler }\end{array}$ & 1.25 & unidirectional & JPF \\
\hline i-TFC & $\begin{array}{l}\text { Sun Medical Co., } \\
\text { Ltd }\end{array}$ & $\begin{array}{l}\text { Glass fibers } \\
\text { Stainless steel (SUS304) }\end{array}$ & 1.30 & bidirectional & $\mathrm{SMF}$ \\
\hline
\end{tabular}

Table 2 Composite resin for core or post fabrication

\begin{tabular}{llll}
\hline Brand name & Manufacturer & Type & Code \\
\hline Unifil Core & GC Corp. & Dual Cure & UC \\
BUILD-IT FR & Pentron Corp. & Dual Cure & BI \\
i-TFC Post Resin & Sun Medical Co., Ltd & Light Cure & IP \\
\hline
\end{tabular}

specimens at room temperature using a universal testing machine (Autograph; AG-I 20kN, Shimadzu, Kyoto Japan). Loading was continued until either the specimen showed catastrophic rupture or load dropped to below $85 \%$ of peak load.

In order to evaluate the effect of cyclic loading on the specimens, three-point loading (span, $15.0 \mathrm{~mm}$; cross-sectional diameter of loading tip, $5 \mathrm{~mm}$ ) was applied at a frequency of $1 \mathrm{~Hz}$ and constant deflection of $0.1,0.2$ and $0.3 \mathrm{~mm}$ using a fatigue testing machine (Servopulser; EHF-FV05-10LA, Shimadzu, Kyoto, Japan). Loading was introduced in sinusoidal fashion at $0.1,0.2$ and $0.3 \mathrm{~mm}$ maximum amplitude and conducted for 1000 cycles, after which the specimens were carefully examined and then tested quasistatically to failure with a three-point bend. A minimum of five tests were conducted for each set of specimens.

\section{Evaluation of fracture mode}

After fracturing, the specimens were observed using a digital microscope (VH5000, Keyence, Tokyo, Japan) and a field emission scanning electron microscope (JSM-6340F, JEOL, Tokyo, Japan) following Au-Pd sputter-coating.

\section{Statistical analysis}

A one-way ANOVA and the Scheffé test $(\alpha=0.05)$ were used to compare differences in strength between specimen groups.

\section{RESULTS}

Static flexure strengths of prefabricated fiber posts, core composite resins and post

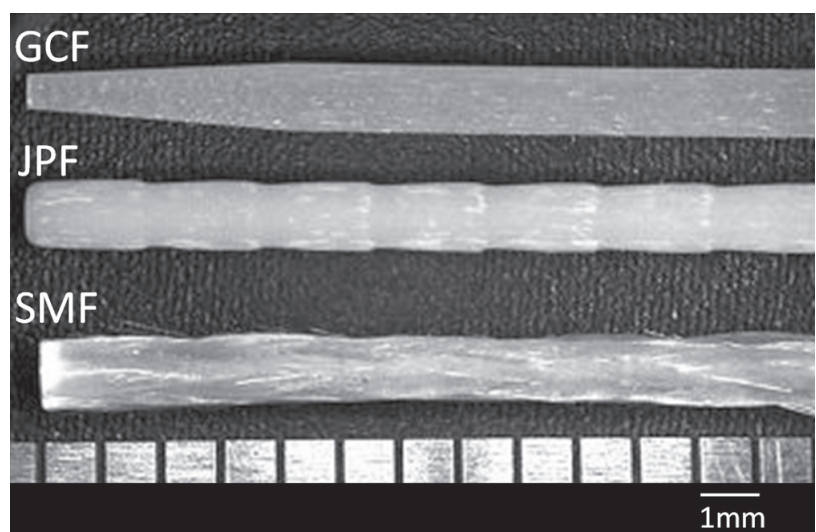

Fig. 1 Appearance of various prefabricated fiber posts.

The flexure strength and elastic modulus of the prefabricated fiber posts is shown in Table 3. GCF showed the highest flexure strength and elastic modulus. SMF showed the lowest flexure strength and elastic modulus. The flexure strength and elastic modulus of each specimen with core composite resin or post are also shown in Table 3. BI showed the highest flexure strength and IP showed the lowest elastic modulus.

\section{Flexure strength after cyclic loading}

Fig. 4 shows the results of the three-point bending test at before and after cyclic loading for composite resin with prefabricated fiber post. Although some specimens showed slight deformation, no catastrophic rupture was observed. The flexure strengths of the composite resin with prefabricated fiber post showed improved strength 


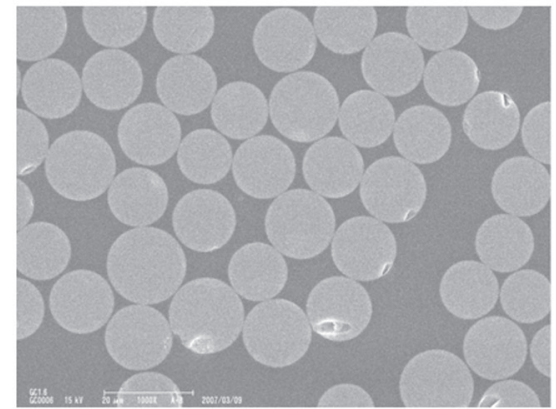

GCF

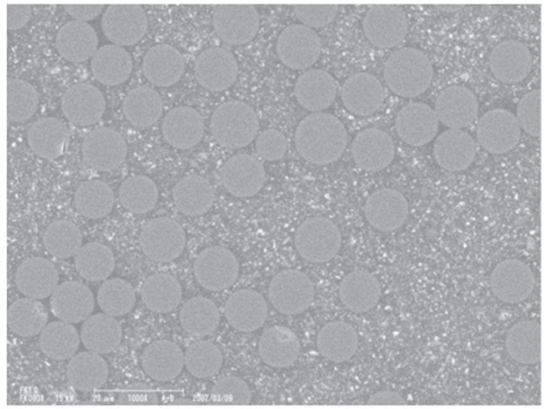

JPF

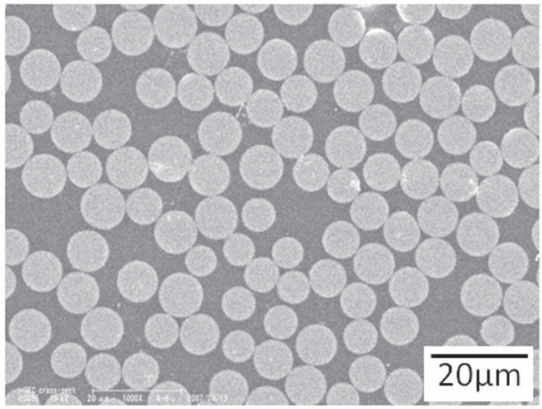

SMF

Fig. 2 SEM-micrographs of cross-sectioned prefabricated fiber posts.

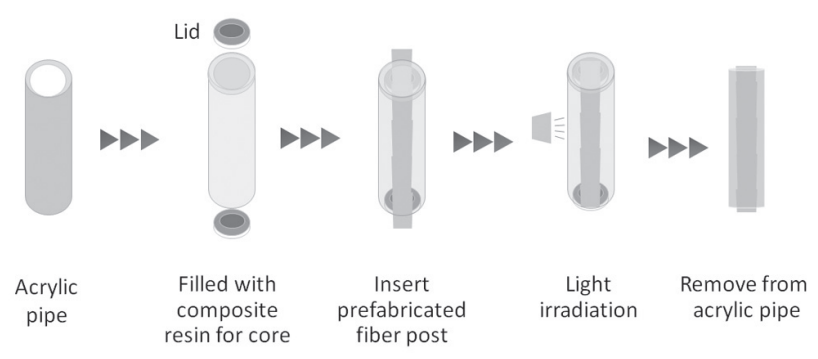

Fig. 3 Sample preparation for composite resin with prefabricated fiber post.

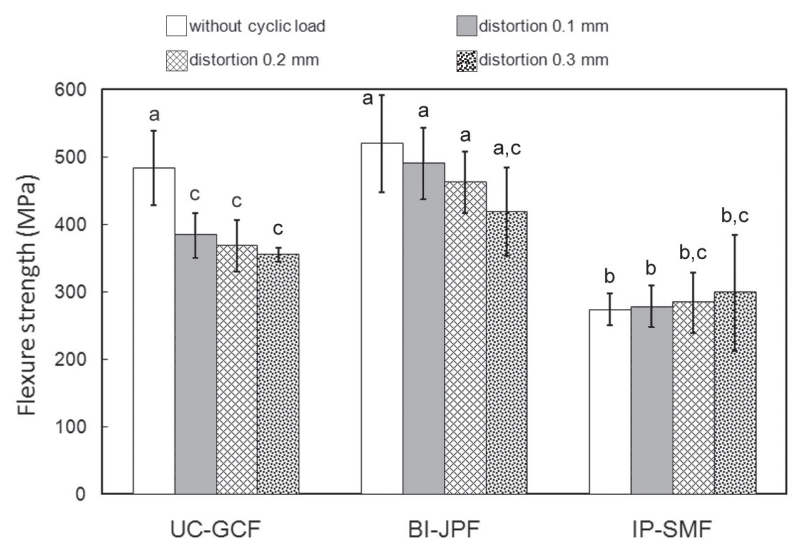

Fig. 4 Maximum flexural strength at before and after cyclic loading 1,000 times for composite resin with prefabricated fiber posts. $(n=5)$ Means with same superscript letter are not significantly different at $p<0.05$.

over that of composite resin alone. With cyclic loading, the flexure strengths of UC-GCF and BI-JPF showed a tendency to decrease with increase in deflection, whereas no such tendency was seen with IP-SMF. No significant difference was observed among the different deflection groups with IP-SMF.
Table 3 Result of static three-point bending test for prefabricated fiber posts and composite resins or post $(n=5) \quad($ ):S.D

\begin{tabular}{lcc}
\hline Code & $\begin{array}{c}\text { Flexure strength } \\
(\mathrm{MPa})\end{array}$ & $\begin{array}{c}\text { Elastic modulus } \\
(\mathrm{GPa})\end{array}$ \\
\hline GCF & $1277(92)$ & $36.6(2.1)$ \\
JPF & $1150(155)$ & $28.4(0.9)$ \\
SMF & $452(89)$ & $25.8(2.2)$ \\
UC & $147(9)$ & $10.6(0.2)$ \\
BI & $183(22)$ & $8.6(0.9)$ \\
IP & $150(10)$ & $5.9(0.2)$ \\
\hline
\end{tabular}

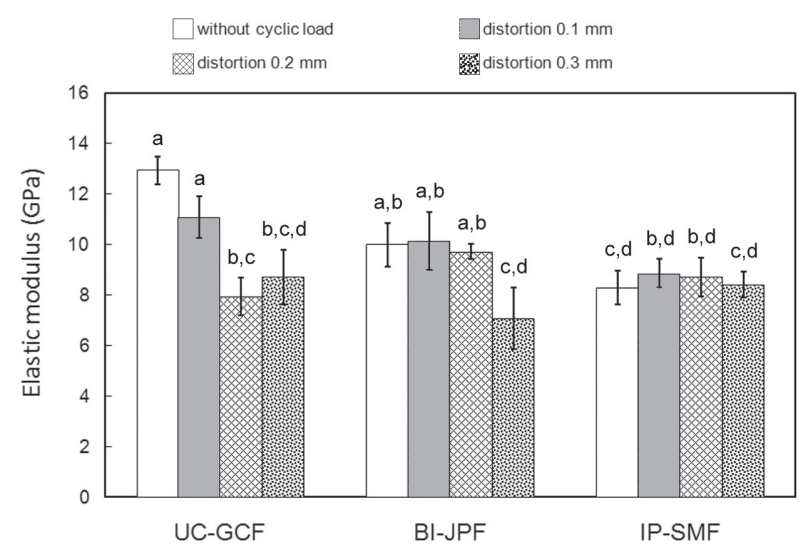

Fig. 5 Elastic modulus at before and after cyclic loading 1,000 times for composite resin with prefabricated fiber posts. $(n=5)$ Means with same superscript letter are not significantly different at $p<0.05$.

Elastic modulus at after cyclic loading

The elastic modulus at before and after cyclic loading for composite resin with prefabricated fiber post is shown in Fig. 5. These specimens showed a higher value than that for composite resin alone at without cyclic loading. After cyclic loading, the elastic modulus 

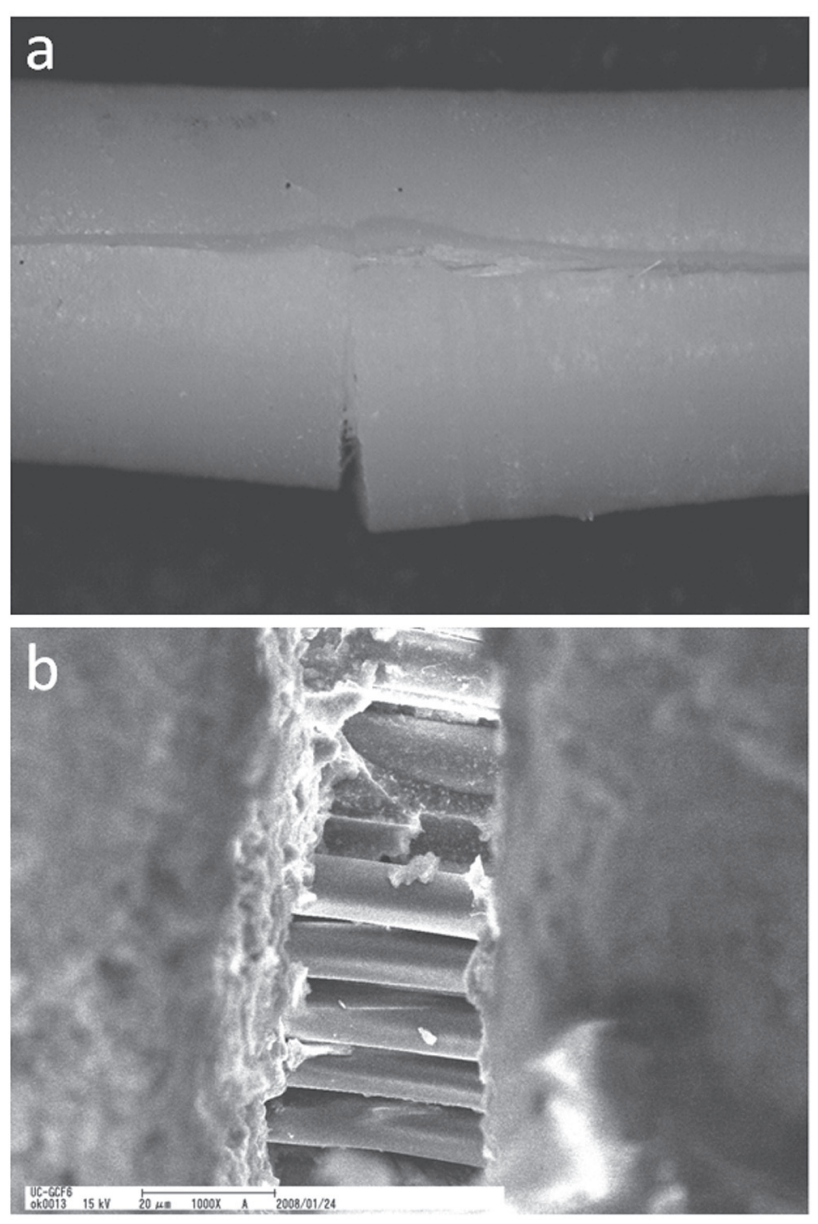

Fig. 6 Optical microscope image (a: UC-GCF) and SEM image (b: UC-GCF) of fractured composite resin with prefabricated fiber post after three-point bending test.

of UC-GCF showed a tendency to decrease with increase in deflection. The elastic modulus was lower than that with composite resin alone at 0.2 or $0.3 \mathrm{~mm}$ deflection with UC-GCF and at $0.3 \mathrm{~mm}$ deflection with BI-JPF. No significant difference was observed between at before and after cyclic loading among the different deflection groups with IP-SMF.

\section{Observation of fracture mode}

The typical fracture pattern is shown in Fig. 6. The crack first appeared on the opposite side to that of the loading point in the three-point bending test, after which the specimen split into two halves along the long axis through the center. Even though the composite resin showed catastrophic rupture, however, the fiber showed no damage. Delamination of glass fibers from the resin matrix was observed.

\section{DISCUSSION}

A post is required to retain the core in endodontically treated teeth. Prefabricated fiber posts offer this capability when used in combination with post-and-core materials and an adhesive resin cement. This study evaluated the flexure strength of unidirectional and bidirectional fiber-reinforced post and core systems. The static flexure test revealed effective fiber reinforcement at before cyclic loading, with flexural strength being enhanced more than 2 times and a 10$30 \%$ increase in elastic modulus over with a composite resin alone. Prefabricated fiber posts contribute great flexural strength and stiffness to core composite resins, regardless of fiber direction. In general, incorporation of glass fiber into a resin enhances the strength of the resin matrix ${ }^{10,11)}$. It is assumed that the bond strength between the prefabricated fiber post and core composite resin is the most important factor among these components. If bonding at this interface is poor, debonding and/or fracture of the post and core will occur. Aksornmuang ${ }^{12)}$ reported that bond strength was enhanced by application of a silane coupling agent. The role of silane coupling agents in increasing bond strength with resin materials is evident in the literature $^{13,14)}$. In this study, all the posts were treated with a silane coupling agent according to the manufacturer's instructions. From the increasing flexural strength and elastic modulus of the results, it seem that proper bond strength was obtained between prefabricated fiber post and core composite resin at before cyclic loading.

In this study, 0.1-0.3 mm of deflection was chosen as the amplitude for cyclic loading. We believed that application of constant stress by cyclic loading was suitable for simulation of masticatory force. However, when constant stress was applied to each specimen at $1 \mathrm{~Hz}$, the low elastic modulus of the composite resin and prefabricated fiber post meant that the specimen had insufficient time to recover its original shape, resulting in major deformation. Therefore, cyclic loading had to be discontinued. Therefore, we adopted constant deflection by cyclic loading. This deflection was equivalent to $20-60 \%(15-45 \mathrm{~N})$ of the maximum fracture load obtained in the static three-point bending test before cyclic loading. Although no specimens showed catastrophic rupture during cyclic loading, the flexure strengths and elastic modulus of UC-GCF and BI-JPF showed a tendency to decrease with increase in deflection. The $0.3-\mathrm{mm}$ deflection specimen, in particular, showed a lower modulus of elasticity than that of core composite resin. This suggests that the reinforcement provided by the prefabricated fiber post was compromised during loading. Although visual examination of the test specimens revealed that they were still intact after cyclic loading, fracture in the composite resin matrix and delamination of glass fibers from the resin matrix were observed after the static three-point bending test (Fig. 6). Application of load at a right angle to the long axis during cyclic loading 
resulted in concentration of load at the interface between the composite resin and the unidirectional fibers because of the large difference in elastic modulus between the core composite resin and unidirectional fibers. Concentrated stress brings on failure of adhesion at the interface of the fiber and the matrix resin, resulting in micro-cracks. These micro-cracks increased with increase in deflection. Therefore, the flexure strengths and elastic modulus of unidirectional fiber specimens showed a tendency to decrease with increase in deflection. These results are in good agreement with those of a previous report ${ }^{15}$.

On the other hand, the bidirectional specimen (IPSMF) showed no significant differences among the different deflection groups. Stress was distributed at the interface because the load acted at an oblique angle to the long axis. This reduced the occurrence of microcracks at the interface. Further study is needed to elucidate the development of the micro-cracks which occur with unidirectional fibers. Moreover, the location of loading point did not take into consideration between cyclic loading and static three-point bending test in this study. As far as the cyclic loading affect flexural strength and elastic modulus, stress distribution should be taken into consideration.

In terms of durability, water sorption into glassfiber reinforced composites raises the additional problem of hydrolytic degradation. Glass fibers containing alkali and earth alkali oxides are susceptible to hydrolytic degradation. Lassila $L^{6} V^{6}$ reported that a decrease in mechanical properties takes place within 30 days of water storage and is caused by plasticization of the polymer matrix by water. With long-term water exposure, hydrolyzation of the silane coupling agent, which is used to promote adhesion between the fibers and the polymer matrix, may affect the mechanical strength of fiber posts. This experiment, however, was carried out under dry conditions. Water storage conditions should be taken into consideration in further study.

\section{CONCLUSIONS}

Prefabricated fiber posts improved the flexural properties of the core composite resin in a post-and-core complex, regardless of fiber direction. However, with cyclic loading, flexural properties deteriorated in the unidirectional fiber post specimens, although no significant difference was observed in the bidirectional fiber post specimen. These results suggest that the direction of the fibers affects the durability of fiberreinforced post and resin core build-up systems.

\section{ACKNOWLEDGMENT}

The authors would like to thank Associate Professor Jeremy Williams, Tokyo Dental College, for his assistance with the English of the manuscript.

\section{REFERENCES}

1) Cagidiaco M C, Goracci C, Garcia-Godoy F, Ferrari M. Clinical studies of fiber posts: a literature review. Int $\mathrm{J}$ Prosthodont 2008; 21: 328-336.

2) Xible AA, Tavarez RR, Araujo Cdos R, Conti PC, Bonachella WC. Effect of cyclic loading on fracture strength of endodontically treated teeth restored with conventional and esthetic posts. J Appl Oral Sci 2006; 14: 297-303.

3) Barjau-Escribano A, Sancho-Bru JL, Forner-Navarro L, Rodríguez-Cervantes PJ, Pérez-Gónzález A, Sánchez-Marín FT. Influence of prefabricated post material on restored teeth: fracture strength and stress distribution. Oper Dent 2006; 31: 47-54.

4) Sirimai S, Riis DN, Morgano SM. An in vitro study of the fracture resistance and the incidence of vertical root fracture of pulpless teeth restored with six post-and-core systems. J Prosthet Dent 1999; 81: 262-269.

5) Mannocci F, Sherriff M, Watson TF. Three-point bending test of fiber posts. J Endo 2001; 27: 758-761.

6) Lassila LV, Tanner J, Le Bell AM, Narva K, Vallittu PK. Flexural properties of fiber reinforced root canal posts. Dent Mater 2004; 20: 29-36.

7) Sheefeld F, Wenz H, Ludwig K, Kern M. Resistance to fracture and structural characteristics of different fiber reinforced post systems. Dent Mater 2007; 23: 265-271.

8) Plotino G, Grande NM, Bedini R, Pameijer CH, Somma F. Flexural properties of endodontic posts and human root dentin. Dent Mater 2007; 23: 1129-1135.

9) Nagase DY, Takemoto S, Hattori M, Yoshinari M, Kawada $\mathrm{E}$, Oda Y. Influence of fabrication techniques on retention force of fiber-reinforced composite posts. Dent Mater J 2005; 24: 280-285.

10) Vallittu PK. Flexural properties of acrylic resin polymers reinforced with unidirectional and woven glass fibers. J Prosthet Dent 1999; 81: 318-326.

11) Goldberg AJ, Freilich MA. An innovative pre-impregnated glass fiber for reinforcing composites. Dent Clin North Am 1999; 43: 127-133.

12) Aksornmuang J, Foxton RM, Nakajima M, Tagami J. Microtensile bond strength of a dual-cure resin core material to glass and quartz fibre posts. J Dent 2004; 32: 443-450.

13) Sahafi A, Peutzfeldt A, Asmussen E, Gotfredsen K. Bond strength of resin cement to dentin and to surface-treated posts of titanium alloy, glass fiber, and zirconia. J Adhes Dent 2003; 5: 153-162.

14) Debnath S, Wunder SL, McCool JI, Baran GR. Silane treatment effects on glass/resin interfacial shear strengths. Dent Mater 2003; 19: 441-448.

15) Bae JM, Kim KN, Hattori M, Hasegawa K, Yoshinari M, Kawada E, Oda Y. Fatigue strengths of particulate filler composites reinforced with fibers. Dent Mater J 2004; 23: 166-174. 